\title{
Intricate transcriptional networks of classical brown and beige fat cells
}

\author{
Jun Hong Park, Wonhee Hur and Sean Bong Lee* \\ Department of Pathology and Laboratory Medicine, Tulane University School of Medicine, New Orleans, LA, USA
}

Brown adipocytes are a specialized cell type that is critical for adaptive thermogenesis, energy homeostasis, and metabolism. In response to cold, both classical brown fat and the newly identified "beige" or "brite" cells are activated by $\beta$-adrenergic signaling and catabolize stored lipids and carbohydrates to produce heat via UCP1. Once thought to be non-existent in adults, recent studies have discovered active classical brown and beige fat cells in humans, thus reinvigorating interest in brown and beige adipocytes. This review will focus on the newly discovered transcription factors and microRNAs that specify and orchestrate the classical brown and beige fat cell development.

\section{OPEN ACCESS}

Edited by:

Jun Wu,

University of Michigan, USA

Reviewed by:

Xingxing Kong,

Harvard Medical School, USA

Paul Cohen,

Rockefeller University, USA

*Correspondence:

Sean Bong Lee,

Department of Pathology and

Laboratory Medicine, Tulane

University School of Medicine,

1700 Tulane Avenue Room 808,

New Orleans, LA 70112, USA

slee30@tulane.edu

Specialty section:

This article was submitted to Cellular

Endocrinology, a section of the

journal Frontiers in Endocrinology

Received: 08 May 2015

Accepted: 24 July 2015

Published: 12 August 2015

Citation:

Park JH, Hur W and Lee SB (2015) Intricate transcriptional networks of classical brown and beige fat cells.

Front. Endocrinol. 6:124.

doi: 10.3389/fendo.2015.00124
Keywords: classical brown fat, beige, brite, transcriptional regulation, transcription factors, miRNAs, lincRNAs

\section{Two Types of Thermogenic Cells: Classical Brown and Beige Fat Cells}

Non-shivering thermogenesis in mammals is carried out by a group of specialized fat cells known as brown adipocytes. Classical brown adipocytes are generated during embryogenesis in distinct brown adipose tissue (BAT) depots, such as the axillary, interscapular, and subscapular regions $(1,2)$. Classical BAT is abundant in rodents and hibernating mammals and it functions to maintain their body temperature in cold climate. Human infants are also born with classical BAT but it disappears over time and was considered to be non-existent in adults (3). However, PET-CT imaging studies with ${ }^{18} \mathrm{~F}$-fluorodeoxyglucose have discovered active BAT in the neck and supraclavicular regions in adult (4-8). These findings have revitalized the research on BAT and the efforts to utilize it as a potential therapy against obesity and other metabolic diseases.

Recent studies in rodents and humans have discovered a second type of brown fat cells known as the beige or brite (brown in white) cells $(2,9)$. Beige cells are generated postnatally within white adipose tissues (WAT) in response to cold or adrenergic stimulation. Both classical brown fat and beige cells are rich in mitochondria and uniquely express uncoupling protein 1 (UCP1), an inner mitochondria membrane protein that produces heat by uncoupling the proton gradient from ATP synthase. Although both brown and beige cells share the same thermogenic function, they arise from entirely different cell lineages $(2,10)$. Classical brown fat cells arise from myogenic progenitors that express Myf5 and Pax7 myogenic transcription factors $(11,12)$ in specific BAT depots during development. In contrast, beige cells are made postnatally in WAT depots and arise from Myf5-precursors that express platelet-derived growth factor receptor $\alpha$ (PDGFR $\alpha)(10,13-$ $15)$ or through transdifferentiation of mature white adipocytes (16-18) in response to cold or $\beta$ adrenergic stimulation. A recent study has also shown that beige cells can arise from smooth muscle cell (Myh11+) progenitors (19). Several mouse genetic lineage-tracing studies have led to discordant results regarding how beige cells are generated $(13,15,17-19)$. The studies that permanently marked mature white adipocytes in subcutaneous (subQ) WAT showed that cold-induced beige cells are derived from mature white adipocytes in subQ WAT $(17,18)$, while another study showed that some 
beige cells are generated de novo from progenitors (15). In contrast, studies that genetically marked PDGFR $\alpha+$ progenitors in epididymal WAT (13) or smooth muscle progenitors (Myh11+) in subQ WAT (19) demonstrated that beige cells are derived from the respective progenitors. While further studies are needed to clarify these issues, these studies clearly demonstrate that different WAT depots have different "browning" capacity and might employ different mechanisms to generate beige cells.

The discovery of active BAT in humans has raised the issue of whether human BATs comprises classical brown or beige fat cells. Several studies have revealed that adult human BAT is more similar to the mouse beige cells $(10,20-22)$, while other studies showed that it is closer to the classical BAT $(23,24)$. Hence, similar to rodents, it is likely that adult humans possess both classical brown and beige fat cells, depending on different anatomical locations.

\section{Preservation of Core Transcriptional Hierarchy in Brown and White Adipogenesis}

During adipogenesis, external adipogenic signals activate a cascade of core transcription factors that are critical for both brown and white adipocyte differentiation. The sequential activation of these transcription factors has been elegantly worked out in 3T3L1 cells (25), which were first established in Howard Green's lab from Swiss albino mouse embryonic fibroblasts (MEFs) (26) using a $3 \mathrm{~T} 3$ protocol (27). Adipogenic stimulation of either white or brown preadipocytes leads to a sequential activation of core transcription factors $(25,28,29)$ (Figure 1). One of the earliest activated transcription factors are CCAAT-enhancer-binding protein- $\beta$ (CEBP- $\beta$ ) and CEBP- $\delta$, which then form a heterodimer and transcriptionally activate peroxisome proliferator-activated receptor $\gamma$ (PPAR $\gamma$ ), along with another family member, CEBP- $\alpha$. PPAR $\gamma$ is a member of the nuclear hormone receptor superfamily and is the master regulator of adipogenesis as its sole expression is sufficient to convert fibroblasts into adipocytes (30). Upon activation, PPAR $\gamma$ activates the transcription of CEBP- $\alpha$ and many other genes involved in fatty acid synthesis, lipid storage, and glucose metabolism (25). CEBP- $\alpha$ then reciprocally activates PPAR $\gamma$ as well as other adipogenic genes. While PPAR $\gamma$ and the CEBPfamily proteins are the core transcriptional regulators of both BAT and WAT adipogenesis, auxiliary transcription factors, such as Kruppel-like factor 5 and 15 (KLF5 and KLF15), also modulate general adipogenesis (25). Interestingly, Zfp423, which contains 30 Kruppel-like zinc fingers and a SMAD-binding domain, was identified as a regulator of preadipocyte determination by activating the transcription of PPAR $\gamma$ (31) (Figure 1). Deletion of $Z f p 423$ in mice inhibits both brown and white adipogenesis.

\section{Transcriptional Regulators of Brown and Beige Fat Cells}

Several recent studies have revealed brown and beige fat-specific transcriptional regulators as well as microRNAs (miRNAs) and long intergenic non-coding RNAs (lincRNAs), which will be described in detail.

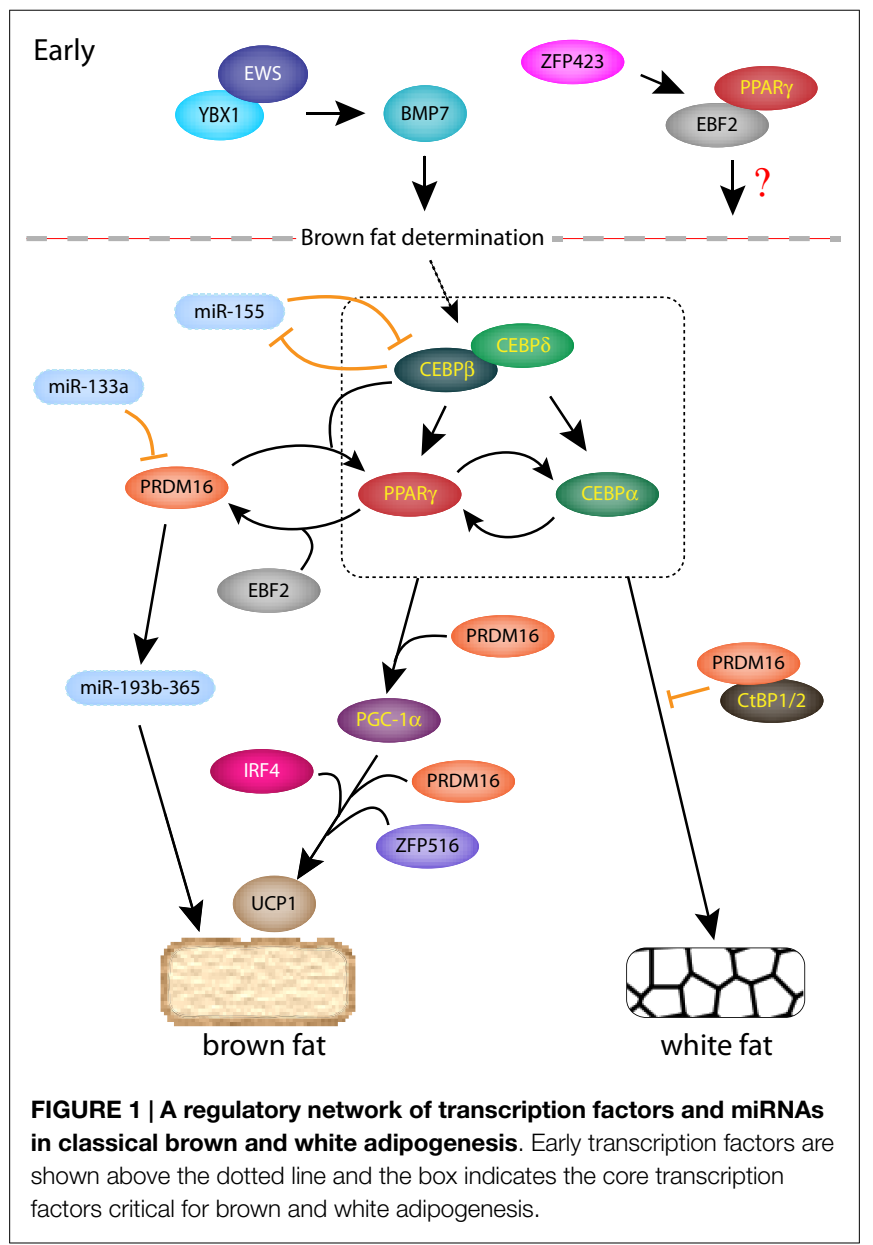

\section{PRD1-BF-1-RIZ1 Homologous-Domain Member 16}

PRD1-BF-1-RIZ1 homologous-Domain Member 16 (PRDM16) and its close homolog PRDM3 were first identified as the histone 3-Lys 9-monomethyltransferases (H3K9me1) that are critical for heterochromatin organization (32). By examining transcriptionrelated genes enriched in brown fat versus white fat, Seale et al. identified PRDM16 as a brown fat-specific transcription factor (33). Ectopic expression of PRDM16 in WAT results in increased beige cell formation in the mouse. Conversely, knockdown of PRDM16 blocks brown fat differentiation. Remarkably, knockdown of PRDM16 in primary brown preadipocytes leads to myocyte differentiation and ectopic PRDM16 expression in myoblasts turns them into brown fat cells upon adipogenic stimulation (11). These results suggest that PRDM16 controls a cell fate switch between brown fat and myocyte differentiation in bipotent progenitors. Interestingly, another H3K9 methyltransferase, EHMT1, interacts with PRDM16 and is required for BAT development (34). PRDM16 forms a complex with CEBP $\beta$ and together, these two factors are able to convert a naïve fibroblasts or myoblasts into brown fat cells (35). Additionally, PRDM16 interacts with $\mathrm{C}$-terminal binding proteins, $\mathrm{CtBP} 1$ and $\mathrm{CtBP} 2$, and represses white fat gene expression program (36), but this 
interaction can be displaced by PGC- $1 \alpha$ or PGC-1 $\beta$, which induces brown fat program upon binding to PRDM16 $(33,36)$. PRDM16 also interacts with PPAR $\gamma$ and enhances its transcriptional activity (11). In addition to cold and $\beta 3$-agonists, PPAR $\gamma$ agonists can also induce beige cell differentiation in the mouse, which was shown to require PRDM16 (37). Addition of PPAR $\gamma$ agonists stabilizes PRDM16, likely through its interaction with $\operatorname{PPAR} \gamma$.

Initial description of global PRDM16 knockout (KO) mice, which was postnatal lethal, reported abnormal BAT morphology with reduced brown fat gene expression and ectopic myogenic gene expression (11). A recent study showed that specific deletion of PRDM16 in postnatal adipose tissues (BAT and WAT) using Adiponectin-Cre blocks cold- or $\beta 3$-agonist-induced browning of subQ WAT, but has minimal effects on classical BAT and visceral (Vis) WAT (38), demonstrating that PRDM16 is essential for beige fat formation in subQ WAT (Figure 2). Furthermore, loss of PRDM16 induces subQ WAT to adopt Vis WAT gene expression profile and reduces its thermogenic capacity. These findings indicate that while PRDM16 is required during early brown cell fate determination (according to earlier studies), it is dispensable for mature BAT thermogenesis. Therefore, it was quite surprising when a specific deletion of PRDM16 in early myogenic progenitors using Myf5-Cre showed normal BAT development (39). In contrast to the Cohen et al. study which reported minimal effects on BAT (38), adult BATs derived from Myf5-specific deletion of PRDM16 shows increased white fat differentiation and reduced thermogenesis in aged animals, suggesting a role of PRDM16 in maintaining mature BAT function (39). A simultaneous deletion of both PRDM16 and its homolog PRDM3 shows much earlier and more prominent brown fat defect than the single PRDM16-KO, although the embryonic and early postnatal (2 weeks) BAT development are minimally affected. These studies show that in the absence of PRDM16, PRDM3 can serve a compensatory role.

\section{FOXC2}

A role of a winged helix/forkhead gene, Foxc2, in browning of white fat was demonstrated well before beige cell was recognized as a distinct cell type (40). Expression of Foxc2 is highly restricted to both BAT and WAT, and adipose-specific expression of Foxc2 using aP2 (Fabp4) promoter in mice results in browning of WAT and hypertrophic BAT. Furthermore, Foxc2 transgenic mice are resistant to high-fat diet (HFD)-induced obesity and insulin and glucose resistance. This is at least partly due to increased mitochondria number and respiration of beige cells in WAT of transgenic mice. Intriguingly, expression of Foxc2 in 3T3-L1 cells blocks white fat differentiation by inhibiting the expression of certain PPAR $\gamma$ target genes (41).

\section{EWS}

Ewing sarcoma break point region 1 (EWSR1, herein termed EWS) encodes a highly abundant, multifunctional RNA/ssDNA binding protein (42). Originally presumed to play housekeeping roles in basic transcription and RNA splicing (43), generation of EWSKO mouse and other studies have revealed a surprisingly diverse role of EWS in meiosis, B-cell development, prevention of cellular senescence, mitosis, DNA damage-induced alternative splicing, and miRNA regulation (44-49). More recently, it was discovered that classical BAT development was completed blocked in EWSKO (50). Deletion of EWS results in a complete block in early

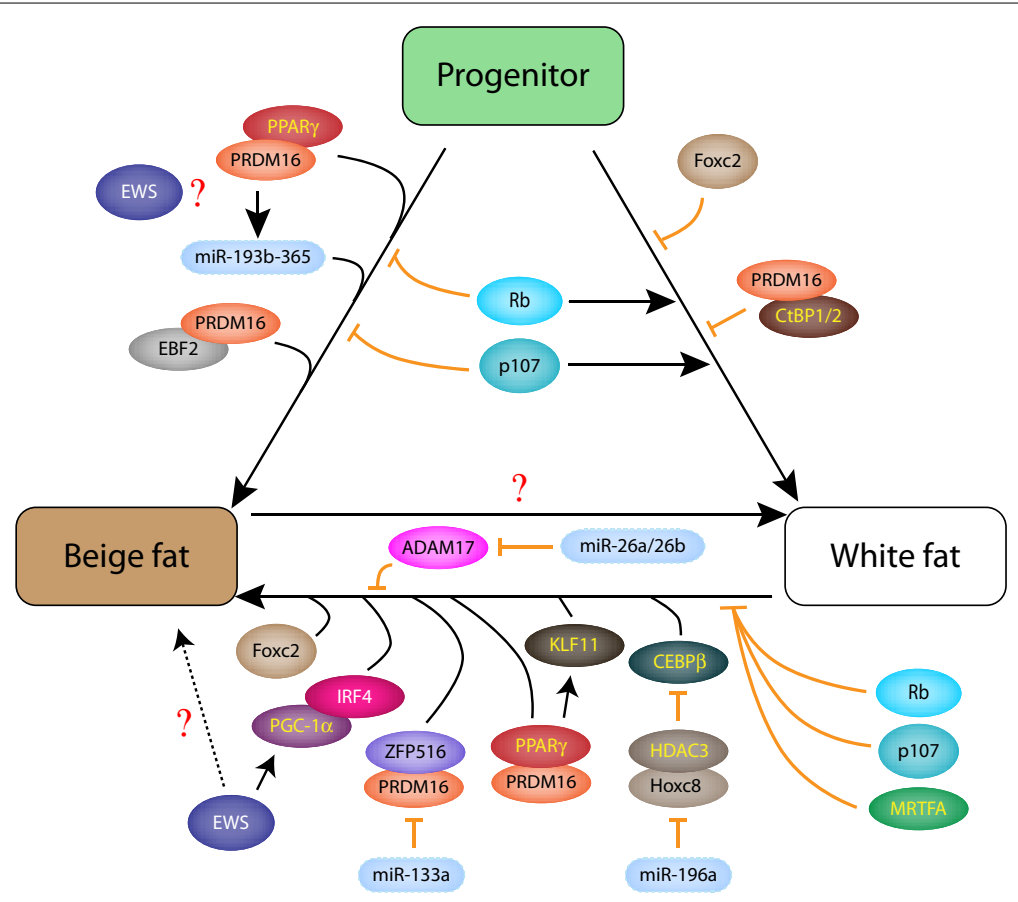

FIGURE 2 | Intricate networks of transcription factors and miRNAs in beige and white fat differentiation from progenitors or through transdifferentiation. 
embryonic classical BAT development and loss of brown fat differentiation in preadipocytes. As a member of TGF- $\beta$ superfamily, BMP7, bone morphogenic protein 7, plays a critical role in the commitment of early mesenchymal progenitors to brown fat (51). In the absence of EWS, BMP7 expression is lost in embryonic BAT and in brown preadipocytes undergoing adipogenesis (50). Following adipogenic stimulation, EWS forms a complex with Y box-binding protein 1 (YBX1) and activates BMP7 transcription. Depletion of YBX1 also results in loss of BMP7 expression and a block in brown fat differentiation. Notably, loss of EWS leads to ectopic myogenic expression in EWS-KO BAT, consistent with the idea that EWS determines the classical brown cell fate. Interestingly, EWS heterozygous mice show reduced beige cell recruitment in inguinal WAT in response to PPAR $\gamma$ agonist or $\beta 3$ adrenergic stimulation (50). However, the definitive role of EWS in beige cell development will require further studies. As both brown fat and beige cells are rich in mitochondria, it is intriguing to note that EWS was recently shown to regulate mitochondria density and function by controlling PGC- $1 \alpha$ protein stability (52). Finally, EWS may also have a role in white adipogenesis, at least in vitro (53).

\section{EBF2}

A search for brown fat-specific PPAR $\gamma$-regulated promoters by ChIP-seq analysis identified an enrichment of early B-cell factor (EBF) binding sites in the PPAR $\gamma$ occupied DNA regions (54). It was subsequently shown that EBF2, one of the four EBF isoforms, is highly expressed in BAT compared to WAT or beige cells. Ectopic expression of EBF2 in $\mathrm{C} 2 \mathrm{C} 12$ myoblasts or in stromal vascular fraction (SVF, which is known to contain adipocyte progenitors) leads to a strong induction of brown fat differentiation, while depletion of EBF2 blocks differentiation in brown preadipocytes. EBF2 recruits PPAR $\gamma$ to the PRDM16 promoter/enhancer region and synergistically activates its expression. EBF2 is expressed in early Myf5+/Pdgfr $\alpha+$ brown progenitors as well as in Pdgfr $\alpha+$ beige precursors from subQ WAT, serving as potential markers of these progenitors (55). However, classical BAT of EBF2 KO mouse shows normal levels of pan-adipocyte markers, PPAR $\gamma$, adiponectin, and Fabp4, but loss of BAT-specific Ucp1, PRDM16, and Cidea expression, demonstrating that EBF2 is not required for general adipogenic process but specifically regulates BAT-specific gene expression $(54,55)$. Interestingly, a recent study showed that EBF2 forms a ribonucleoprotein complex with a long non-coding RNA (IncRNA) termed brown fat lncRNA 1 (Blnc1), which is transcriptionally regulated by EBF2 during brown adipogenesis, to promote adipogenesis in brown adipocytes (56).

\section{KLF11, IRF4, and ZFP516}

As aforementioned and reviewed in Ref. $(25,57)$, several KLFfamily proteins play important roles in the common adipogenic differentiation of BAT and WAT. Notably, KLF11 was recently identified as an activator of beige cell differentiation of human adipose-derived stem cells (58). KLF11 is a direct target of PPAR $\gamma$ and activates the expression of beige-specific genes. Expression of interferon regulatory factor 4 (IRF4) is induced by cold in both BAT and WAT and overexpression of IRF4 in BAT and WAT leads to enhanced thermogenesis and resistance to HFD-induced obesity (59). Conversely, specific deletion of IRF4 in Ucp1+ cells (brown and beige cells) causes a reduction in energy expenditure and thermogenesis as well a block in beige cell formation in subQ WAT. Interestingly, PGC- $1 \alpha$ interacts with IRF4 and this interaction appeared to be crucial for activation of Ucp1 expression. A search for transcription factors that directly activate Ucp1 led to an identification of $\mathrm{Zfp} 516$ containing ten $\mathrm{C} 2 \mathrm{H} 2$ zinc finger protein (60). Ectopic expression or genetic deletion of Zfp516 results in browning of WAT or loss of classical BAT development. Though the exact mechanisms of Zfp516 are not clear, it interacts with PRDM16; however, since PRDM16 is dispensable for classical BAT development, how Zfp516 regulates BAT development remains unresolved.

\section{Inhibitors of Brown and Beige Cell Differentiation: Rb Family Proteins and MRTFA}

Retinoblastoma susceptibility $(\mathrm{Rb})$ family proteins, $\mathrm{Rb}$ and $\mathrm{p} 107$, have important roles in determining white versus brown adipocyte differentiation $(61,62)$. Deletion of $R b$ in MEFs or embryonic stem (ES) cells results in brown fat differentiation $(\mathrm{Ucp} 1+)$ upon adipogenic stimulation while control cells give rise to white adipocytes (61). Consistent with this, mesenchymal progenitorspecific Rb KO embryos show a significant increase in classical BAT mass (63). Intriguingly, while $\mathrm{Rb}$ is required for white adipocyte differentiation in vitro $(64,65)$, adipose-specific $\mathrm{KO}$ of $\mathrm{Rb}(66)$ or inactivation of $\mathrm{Rb}$ via SV40 $\mathrm{T}$ antigen in WAT (67) results in browning of WAT. Expression of p107 is abundant in the SVF from Vis WAT, lower in subQ WAT, and absent in BAT (68). Mature white adipocytes from any WAT depots do not express p107. Deletion of p107 in a congenic Balb/c background leads to an impairment of WAT development but not BAT, and causes extensive browning in various WAT depots (62). $\beta$-adrenergic stimulation reduces p107 expression in SVF and induces beige fat differentiation (68). Thus, $\mathrm{Rb}$ family proteins likely function as a negative regulator of beige cell differentiation. Similarly, genetic ablation of myocardin-related transcription factor A (MRTFA) results in browning of WAT depots without affecting BAT mass and function (69). MRTFA KO mice are protected from HFD-induced obesity and insulin resistance, demonstrating that MRTFA is a negative regulator of beige cell formation.

\section{Regulation of Brown and Beige Cell by microRNAs}

Recent studies have identified several miRNAs that specifically target the expression of critical brown or beige transcription factors described above. Accordingly, many miRNAs are expressed in BAT- or WAT-specific manner. One such miRNA, miR-193b-365, is activated by PRDM16 and is required for brown adipogenesis (70) (Figure 1). Forced expression of miR-193b-365 in myoblasts blocks myogenesis and upon adipogenic stimulation, induces brown fat differentiation. In contrast, miR-133a represses PRDM16 expression 
and inhibits brown fat differentiation by targeting the $3^{\prime}$-UTR of PRDM16 transcripts $(71,72)$. Genetic inactivation of miR133a has no effects on BAT development but increases beige cell development in WAT depots, which results in improved thermogenesis and glucose and insulin sensitivity. TGF $\beta$, a potent inhibitor of adipogenesis (73), increases the expression of miR-155 and inhibits adipogenesis (74). Inhibition of adipogenesis by miR155 overexpression suppresses CEBP $\beta$ expression, while CEBP $\beta$ represses miR-155 expression, forming a double negative loop in brown adipogenesis (Figure 1). Ectopic expression of miR-155 in the mouse reduces BAT size and function while miR-155 KO mice show improved BAT thermogenesis and enhanced beige cell formation in WAT. Expression of miR-196a is induced in subQ WAT following cold or $\beta 3$-agonist stimulation and is required for Ucp1 expression (75). miR-196a represses the expression Hoxc8, homeobox c8, which is highly expressed in white fat cells and inhibits brown fat differentiation. Adipose-specific expression of miR-196a results in enhanced browning of WAT and protects mice from HFD-induced obesity and insulin resistance. Intriguingly, it was found that Hoxc8 represses CEBP $\beta$ expression by recruiting histone deacetylase, HDAC3. Thus, miR-196a regulates the expression of CEBP $\beta$ through Hoxc8 (Figure 2). miR-26a and miR-26b also have positive effects on converting human

\section{References}

1. Frontini A, Cinti S. Distribution and development of brown adipocytes in the murine and human adipose organ. Cell Metab (2010) 11:253-6. doi:10.1016/j. cmet.2010.03.004

2. Rosen ED, Spiegelman BM. What we talk about when we talk about fat. Cell (2014) 156:20-44. doi:10.1016/j.cell.2013.12.012

3. Nedergaard J, Cannon B. The changed metabolic world with human brown adipose tissue: therapeutic visions. Cell Metab (2010) 11:268-72. doi:10.1016/j. cmet.2010.03.007

4. Cypess AM, Lehman S, Williams G, Tal I, Rodman D, Goldfine AB, et al. Identification and importance of brown adipose tissue in adult humans. N Engl J Med (2009) 360:1509-17. doi:10.1056/NEJMoa0810780

5. van Marken Lichtenbelt WD, Vanhommerig JW, Smulders NM, Drossaerts JM, Kemerink GJ, Bouvy ND, et al. Cold-activated brown adipose tissue in healthy men. N Engl J Med (2009) 360:1500-8. doi:10.1056/NEJMoa0808718

6. Virtanen KA, Lidell ME, Orava J, Heglind M, Westergren R, Niemi T, et al. Functional brown adipose tissue in healthy adults. N Engl J Med (2009) 360:1518-25. doi:10.1056/NEJMoa0808949

7. Zingaretti MC, Crosta F, Vitali A, Guerrieri M, Frontini A, Cannon B, et al. The presence of UCP1 demonstrates that metabolically active adipose tissue in the neck of adult humans truly represents brown adipose tissue. FASEB J (2009) 23:3113-20. doi:10.1096/fj.09-133546

8. Saito M, Okamatsu-Ogura Y, Matsushita M, Watanabe K, Yoneshiro T, NioKobayashi J, et al. High incidence of metabolically active brown adipose tissue in healthy adult humans: effects of cold exposure and adiposity. Diabetes (2009) 58:1526-31. doi:10.2337/db09-0530

9. Kajimura S, Saito M. A new era in brown adipose tissue biology: molecular control of brown fat development and energy homeostasis. Annu Rev Physiol (2014) 76:225-49. doi:10.1146/annurev-physiol-021113-170252

10. Wu J, Bostrom P, Sparks LM, Ye L, Choi JH, Giang AH, et al. Beige adipocytes are a distinct type of thermogenic fat cell in mouse and human. Cell (2012) 150:366-76. doi:10.1016/j.cell.2012.05.016

11. Seale P, Bjork B, Yang W, Kajimura S, Chin S, Kuang S, et al. PRDM16 controls a brown fat/skeletal muscle switch. Nature (2008) 454:961-7. doi:10. 1038/nature07182

12. Lepper C, Fan CM. Inducible lineage tracing of Pax7-descendant cells reveals embryonic origin of adult satellite cells. Genesis (2010) 48:424-36. doi:10.1002/ dvg.20630 preadipocytes into beige cells (76). This is mediated by repressing ADAM17, ADAM metallopeptidase domain 17, expression and knockdown of ADAM17 recapitulates the increased beige adipogenesis. On the flip side, $\mathrm{miR}-27 \mathrm{a} / \mathrm{b}$ negatively regulates multiple critical regulators of brown and beige adipogenesis, such as PRDM16, PPAR $\gamma$, and PGC-1 $\beta$, and its expression is repressed by cold exposure in BAT and subQ WAT (77).

In this short review, we highlighted the roles of the transcriptional regulators and miRNAs on brown and beige cell differentiation and function. While we have learned a great deal about brown and beige fat cells, there are still many unanswered questions. Recent studies suggest that cold- or $\beta$-adrenergic-stimulated induction of beige cells in WAT is transient and reversible (i.e., reversible transdifferentiation between mature white fat and beige cells) $(17,18)$. To achieve this plasticity, mature white fat and beige cells must have mechanisms to tightly and reciprocally regulate many of the beige-specific transcriptional regulators and miRNAs during this reversible process (Figure 2). As exemplified by the CEBP $\beta$-miR-155 regulatory loop (75), delineating the intricate details of the interdependence and cross-regulation of the transcription factor and miRNA networks will provide a deeper understanding of brown and beige fat differentiation and facilitate the development of brown or beige cell-based therapy.

13. Lee YH, Petkova AP, Mottillo EP, Granneman JG. In vivo identification of bipotential adipocyte progenitors recruited by beta3-adrenoceptor activation and high-fat feeding. Cell Metab (2012) 15:480-91. doi:10.1016/j.cmet.2012.03. 009

14. Schulz TJ, Huang TL, Tran TT, Zhang H, Townsend KL, Shadrach JL, et al. Identification of inducible brown adipocyte progenitors residing in skeletal muscle and white fat. Proc Natl Acad Sci U S A (2011) 108:143-8. doi:10.1073/ pnas. 1010929108

15. Wang QA, Tao C, Gupta RK, Scherer PE. Tracking adipogenesis during white adipose tissue development, expansion and regeneration. Nat Med (2013) 19:1338-44. doi:10.1038/nm.3324

16. Barbatelli G, Murano I, Madsen L, Hao Q, Jimenez M, Kristiansen K, et al. The emergence of cold-induced brown adipocytes in mouse white fat depots is determined predominantly by white to brown adipocyte transdifferentiation. Am J Physiol Endocrinol Metab (2010) 298:E1244-53. doi:10.1152/ajpendo. 00600.2009

17. Lee YH, Petkova AP, Konkar AA, Granneman JG. Cellular origins of coldinduced brown adipocytes in adult mice. FASEB J (2015) 29:286-99. doi:10. 1096/fj.14-263038

18. Rosenwald M, Perdikari A, Rulicke T, Wolfrum C. Bi-directional interconversion of brite and white adipocytes. Nat Cell Biol (2013) 15:659-67. doi:10.1038/ ncb2740

19. Long JZ, Svensson KJ, Tsai L, Zeng X, Roh HC, Kong X, et al. A smooth musclelike origin for beige adipocytes. Cell Metab (2014) 19:810-20. doi:10.1016/j. cmet.2014.03.025

20. Lee P, Werner CD, Kebebew E, Celi FS. Functional thermogenic beige adipogenesis is inducible in human neck fat. Int J Obes (Lond) (2014) 38:170-6. doi:10.1038/ijo.2013.82

21. Sharp LZ, Shinoda K, Ohno H, Scheel DW, Tomoda E, Ruiz L, et al. Human BAT possesses molecular signatures that resemble beige/brite cells. PLoS One (2012) 7:e49452. doi:10.1371/journal.pone.0049452

22. Shinoda K, Luijten IH, Hasegawa Y, Hong $H$, Sonne SB, Kim M, et al. Genetic and functional characterization of clonally derived adult human brown adipocytes. Nat Med (2015) 21:389-94. doi:10.1038/ nm.3819

23. Jespersen NZ, Larsen TJ, Peijs L, Daugaard S, Homoe P, Loft A, et al. A classical brown adipose tissue mRNA signature partly overlaps with brite in the supraclavicular region of adult humans. Cell Metab (2013) 17:798-805. doi:10.1016/j.cmet.2013.04.011 
24. Cypess AM, White AP, Vernochet C, Schulz TJ, Xue R, Sass CA, et al. Anatomical localization, gene expression profiling and functional characterization of adult human neck brown fat. Nat Med (2013) 19:635-9. doi:10.1038/ nm.3112

25. Rosen ED, MacDougald OA. Adipocyte differentiation from the inside out. Nat Rev Mol Cell Biol (2006) 7:885-96. doi:10.1038/nrm2066

26. Green $H$, Meuth $M$. An established pre-adipose cell line and its differentiation in culture. Cell (1974) 3:127-33. doi:10.1016/0092-8674(74)90116-0

27. Todaro GJ, Green H. Quantitative studies of the growth of mouse embryo cells in culture and their development into established lines. J Cell Biol (1963) 17:299-313. doi:10.1083/jcb.17.2.299

28. Farmer SR. Molecular determinants of brown adipocyte formation and function. Genes Dev (2008) 22:1269-75. doi:10.1101/gad.1681308

29. Kajimura S, Seale P, Spiegelman BM. Transcriptional control of brown fat development. Cell Metab (2010) 11:257-62. doi:10.1016/j.cmet.2010.03.005

30. Tontonoz P, Hu E, Spiegelman BM. Stimulation of adipogenesis in fibroblasts by PPAR gamma 2, a lipid-activated transcription factor. Cell (1994) 79:1147-56. doi:10.1016/0092-8674(94)90006-X

31. Gupta RK, Arany Z, Seale P, Mepani RJ, Ye L, Conroe HM, et al. Transcriptional control of preadipocyte determination by Zfp423. Nature (2010) 464:619-23. doi:10.1038/nature08816

32. Pinheiro I, Margueron R, Shukeir N, Eisold M, Fritzsch C, Richter FM, et al. Prdm3 and Prdm16 are H3K9me1 methyltransferases required for mammalian heterochromatin integrity. Cell (2012) 150:948-60. doi:10.1016/j.cell.2012.06. 048

33. Seale P, Kajimura S, Yang W, Chin S, Rohas LM, Uldry M, et al. Transcriptional control of brown fat determination by PRDM16. Cell Metab (2007) 6:38-54. doi:10.1016/j.cmet.2007.06.001

34. Ohno H, Shinoda K, Ohyama K, Sharp LZ, Kajimura S. EHMT1 controls brown adipose cell fate and thermogenesis through the PRDM16 complex. Nature (2013) 504:163-7. doi:10.1038/nature12652

35. Kajimura S, Seale P, Kubota K, Lunsford E, Frangioni JV, Gygi SP, et al. Initiation of myoblast to brown fat switch by a PRDM16-C/EBP-beta transcriptional complex. Nature (2009) 460:1154-8. doi:10.1038/nature08262

36. Kajimura S, Seale P, Tomaru T, Erdjument-Bromage H, Cooper MP, Ruas $\mathrm{JL}$, et al. Regulation of the brown and white fat gene programs through a PRDM16/CtBP transcriptional complex. Genes Dev (2008) 22:1397-409. doi: 10.1101/gad.1666108

37. Ohno H, Shinoda K, Spiegelman BM, Kajimura S. PPARgamma agonists induce a white-to-brown fat conversion through stabilization of PRDM16 protein. Cell Metab (2012) 15:395-404. doi:10.1016/j.cmet.2012.01.019

38. Cohen P, Levy JD, Zhang Y, Frontini A, Kolodin DP, Svensson KJ, et al. Ablation of PRDM16 and beige adipose causes metabolic dysfunction and a subcutaneous to visceral fat switch. Cell (2014) 156:304-16. doi:10.1016/j.cell. 2013.12.021

39. Harms MJ, Ishibashi J, Wang W, Lim HW, Goyama S, Sato T, et al. Prdm16 is required for the maintenance of brown adipocyte identity and function in adult mice. Cell Metab (2014) 19:593-604. doi:10.1016/j.cmet.2014.03.007

40. Cederberg A, Gronning LM, Ahren B, Tasken K, Carlsson P, Enerback S. FOXC2 is a winged helix gene that counteracts obesity, hypertriglyceridemia, and diet-induced insulin resistance. Cell (2001) 106:563-73. doi:10.1016/ S0092-8674(01)00474-3

41. Davis KE, Moldes M, Farmer SR. The forkhead transcription factor FoxC2 inhibits white adipocyte differentiation. J Biol Chem (2004) 279:42453-61. doi:10.1074/jbc.M402197200

42. Paronetto MP. Ewing sarcoma protein: a key player in human cancer. Int J Cell Biol (2013) 2013:642853. doi:10.1155/2013/642853

43. Tan AY, Manley JL. The TET family of proteins: functions and roles in disease. J Mol Cell Biol (2009) 1:82-92. doi:10.1093/jmcb/mjp025

44. Cho J, Shen H, Yu H, Li H, Cheng T, Lee SB, et al. Ewing sarcoma gene Ews regulates hematopoietic stem cell senescence. Blood (2011) 117:1156-66. doi:10.1182/blood-2010-04-279349

45. Li H, Watford W, Li C, Parmelee A, Bryant MA, Deng C, et al. Ewing sarcoma gene EWS is essential for meiosis and B lymphocyte development. J Clin Invest (2007) 117:1314-23. doi:10.1172/JCI31222

46. Kim KY, Hwang YJ, Jung MK, Choe J, Kim Y, Kim S, et al. A multifunctional protein EWS regulates the expression of Drosha and microRNAs. Cell Death Differ (2013) 21(1):136-45. doi:10.1038/cdd.2013.144
47. Azuma M, Embree LJ, Sabaawy H, Hickstein DD. Ewing sarcoma protein ewsr1 maintains mitotic integrity and proneural cell survival in the zebrafish embryo. PLoS One (2007) 2:e979. doi:10.1371/journal.pone.0000979

48. Dutertre M, Sanchez G, De Cian MC, Barbier J, Dardenne E, Gratadou L, et al. Cotranscriptional exon skipping in the genotoxic stress response. Nat Struct Mol Biol (2010) 17:1358-66. doi:10.1038/nsmb.1912

49. Paronetto MP, Minana B, Valcarcel J. The Ewing sarcoma protein regulates DNA damage-induced alternative splicing. Mol Cell (2011) 43:353-68. doi:10. 1016/j.molcel.2011.05.035

50. Park JH, Kang HJ, Kang SI, Lee JE, Hur J, Ge K, et al. A multifunctional protein, EWS, is essential for early brown fat lineage determination. Dev Cell (2013) 26:393-404. doi:10.1016/j.devcel.2013.07.002

51. Tseng YH, Kokkotou E, Schulz TJ, Huang TL, Winnay JN, Taniguchi CM, et al. New role of bone morphogenetic protein 7 in brown adipogenesis and energy expenditure. Nature (2008) 454:1000-4. doi:10.1038/nature07221

52. Park JH, Kang HJ, Lee YK, Kang H, Kim J, Chung JH, et al. Inactivation of EWS reduces PGC-1alpha protein stability and mitochondrial homeostasis. Proc Natl Acad Sci U S A (2015) 112:6074-9. doi:10.1073/pnas. 1504391112

53. Park JH, Lee SB. An essential role for Ewing sarcoma gene (EWS) in early white adipogenesis. Obesity (2015) 23:138-44. doi:10.1002/oby.20934

54. Rajakumari S, Wu J, Ishibashi J, Lim HW, Giang AH, Won KJ, et al. EBF2 determines and maintains brown adipocyte identity. Cell Metab (2013) 17:562-74. doi:10.1016/j.cmet.2013.01.015

55. Wang W, Kissig M, Rajakumari S, Huang L, Lim HW, Won KJ, et al. Ebf2 is a selective marker of brown and beige adipogenic precursor cells. Proc Natl Acad Sci U S A (2014) 111:14466-71. doi:10.1073/pnas.1412685111

56. Zhao XY, Li S, Wang GX, Yu Q, Lin JD. A long noncoding RNA transcriptional regulatory circuit drives thermogenic adipocyte differentiation. Mol Cell (2014) 55:372-82. doi:10.1016/j.molcel.2014.06.004

57. Wu Z, Wang S. Role of kruppel-like transcription factors in adipogenesis. Dev Biol (2013) 373:235-43. doi:10.1016/j.ydbio.2012.10.031

58. Loft A, Forss I, Siersbaek MS, Schmidt SF, Larsen AS, Madsen JG, et al. Browning of human adipocytes requires KLF11 and reprogramming of PPARgamma superenhancers. Genes Dev (2015) 29:7-22. doi:10.1101/gad.250829.114

59. Kong X, Banks A, Liu T, Kazak L, Rao RR, Cohen P, et al. IRF4 is a key thermogenic transcriptional partner of PGC-1alpha. Cell (2014) 158:69-83. doi:10.1016/j.cell.2014.04.049

60. Dempersmier J, Sambeat A, Gulyaeva O, Paul SM, Hudak CS, Raposo HF, et al. Cold-inducible Zfp516 activates UCP1 transcription to promote browning of white fat and development of brown fat. Mol Cell (2015) 57:235-46. doi:10.1016/ j.molcel.2014.12.005

61. Hansen JB, Jorgensen C, Petersen RK, Hallenborg P, De Matteis R, Boye HA, et al. Retinoblastoma protein functions as a molecular switch determining white versus brown adipocyte differentiation. Proc Natl Acad Sci U S A (2004) 101:4112-7. doi:10.1073/pnas.0301964101

62. Scime A, Grenier G, Huh MS, Gillespie MA, Bevilacqua L, Harper ME, et al $\mathrm{Rb}$ and p107 regulate preadipocyte differentiation into white versus brown fat through repression of PGC-1alpha. Cell Metab (2005) 2:283-95. doi:10.1016/j. cmet.2005.10.002

63. Calo E, Quintero-Estades JA, Danielian PS, Nedelcu S, Berman SD, Lees $\mathrm{JA}$. $\mathrm{Rb}$ regulates fate choice and lineage commitment in vivo. Nature (2010) 466:1110-4. doi:10.1038/nature09264

64. Higgins C, Chatterjee S, Cherington V. The block of adipocyte differentiation by a C-terminally truncated, but not by full-length, simian virus 40 large tumor antigen is dependent on an intact retinoblastoma susceptibility protein family binding domain. J Virol (1996) 70:745-52.

65. Classon M, Kennedy BK, Mulloy R, Harlow E. Opposing roles of pRB and p107 in adipocyte differentiation. Proc Natl Acad Sci U S A (2000) 97:10826-31. doi:10.1073/pnas.190343597

66. Dali-Youcef N, Mataki C, Coste A, Messaddeq N, Giroud S, Blanc S, et al. Adipose tissue-specific inactivation of the retinoblastoma protein protects against diabesity because of increased energy expenditure. Proc Natl Acad Sci U S A (2007) 104:10703-8. doi:10.1073/pnas.0611568104

67. Ross SR, Choy L, Graves RA, Fox N, Solevjeva V, Klaus S, et al. Hibernoma formation in transgenic mice and isolation of a brown adipocyte cell line expressing the uncoupling protein gene. Proc Natl Acad Sci U S A (1992) 89:7561-5. doi:10.1073/pnas.89.16.7561 
68. De Sousa M, Porras DP, Perry CG, Seale P, Scime A. p107 is a crucial regulator for determining the adipocyte lineage fate choices of stem cells. Stem Cells (2014) 32:1323-36. doi:10.1002/stem.1637

69. McDonald ME, Li C, Bian H, Smith BD, Layne MD, Farmer SR. Myocardinrelated transcription factor A regulates conversion of progenitors to beige adipocytes. Cell (2015) 160:105-18. doi:10.1016/j.cell.2014.12.005

70. Sun L, Xie H, Mori MA, Alexander R, Yuan B, Hattangadi SM, et al. Mir193b365 is essential for brown fat differentiation. Nat Cell Biol (2011) 13:958-65. doi: $10.1038 /$ ncb2286

71. Liu W, Bi P, Shan T, Yang X, Yin H, Wang YX, et al. miR-133a regulates adipocyte browning in vivo. PLoS Genet (2013) 9:e1003626. doi:10.1371/ journal.pgen.1003626

72. Trajkovski M, Ahmed K, Esau CC, Stoffel M. MyomiR-133 regulates brown fat differentiation through Prdm16. Nat Cell Biol (2012) 14:1330-5. doi:10.1038/ ncb2612

73. Ignotz RA, Massague J. Type beta transforming growth factor controls the adipogenic differentiation of 3T3 fibroblasts. Proc Natl Acad Sci U S A (1985) 82:8530-4. doi:10.1073/pnas.82.24.8530

74. Chen Y, Siegel F, Kipschull S, Haas B, Frohlich H, Meister G, et al. miR-155 regulates differentiation of brown and beige adipocytes via a bistable circuit. Nat Commun (2013) 4:1769. doi:10.1038/ncomms 2742
75. Mori M, Nakagami H, Rodriguez-Araujo G, Nimura K, Kaneda Y. Essential role for miR-196a in brown adipogenesis of white fat progenitor cells. PLoS Biol (2012) 10:e1001314. doi:10.1371/journal.pbio.1001314

76. Karbiener M, Pisani DF, Frontini A, Oberreiter LM, Lang E, Vegiopoulos A, et al. MicroRNA-26 family is required for human adipogenesis and drives characteristics of brown adipocytes. Stem Cells (2014) 32:1578-90. doi:10.1002/ stem. 1603

77. Sun L, Trajkovski M. MiR-27 orchestrates the transcriptional regulation of brown adipogenesis. Metabolism (2014) 63:272-82. doi:10.1016/j.metabol. 2013.10.004

Conflict of Interest Statement: The authors declare that the research was conducted in the absence of any commercial or financial relationships that could be construed as a potential conflict of interest.

Copyright (C) 2015 Park, Hur and Lee. This is an open-access article distributed under the terms of the Creative Commons Attribution License (CC BY). The use, distribution or reproduction in other forums is permitted, provided the original author(s) or licensor are credited and that the original publication in this journal is cited, in accordance with accepted academic practice. No use, distribution or reproduction is permitted which does not comply with these terms. 